\title{
A Correlation between Histochemical Patterns of Connective Tissue Fibers and AgNORs in Breast Lesions
}

\author{
Abdelbaset Mohamed Elasbali \\ Department of Clinical Laboratory Sciences, College of Applied Medical Sciences, Jouf University, Qurayyat, KSA \\ Email: hussaingad5@gmail.com
}

How to cite this paper: Elasbali, A.M. (2019) A Correlation between Histochemical Patterns of Connective Tissue Fibers and AgNORs in Breast Lesions. Open Journal of Pathology, 9, 29-39.

https://doi.org/10.4236/ojpathology.2019.9 $\underline{2004}$

Received: March 11, 2019

Accepted: April 9, 2019

Published: April 12, 2019

Copyright () 2019 by author(s) and Scientific Research Publishing Inc. This work is licensed under the Creative Commons Attribution International License (CC BY 4.0).

http://creativecommons.org/licenses/by/4.0/

\begin{abstract}
Background: The precise histopathologic diagnosis of a breast lesion is the first step towards the most appropriate inclusive patient's management. The aim of this study was to evaluate the correlation between histochemical patterns of connective tissue fibers and NORs in breast lesions. Methodology: Patients with breast cancer $(n=25)$ were ascertained as the case group, and those with benign breast lesions were ascertained as a control group $(n=25)$. Histochemical evaluations of elastic fibers, reticular fibers and mean AgNORs count were performed for all study subjects. Results: Elastic fibers intensity was brought into being lessening in benign lesions and upturns in the direction of malignant lesions. The intensity of elastic fibers was found to intensify with rises of neoplastic changes in breast cancer and this was found to be statistically significant $\mathrm{P}<0.001$. Mean AgNORs counts displayed increased clusters among malignant cases equated to benign ones. Mean AgNORs count significantly increased with neoplastic proliferation $\mathrm{P}<0.005$. Conclusion: Demonstration of connective tissue fibers (particularly elastic fibers) can strength the diagnostic evidence for conventional histopathology diagnosis. Mean AgNORs count can merge as an important quantitative marker in breast cancer diagnosis.
\end{abstract}

\section{Keywords}

Breast Cancer, Elastic Fiber, Reticular Fiber, AgNORs, Breast Lesions

\section{Introduction}

Breast cancer incidence rate (11.6\% for both sexes) is among the highest cancer incidence rates worldwide [1]. Some benign breast lesions and in situ breast carcinoma are associated with an increased risk of developing invasive breast cancer 
[2]. Although the benign or malignant pattern of the lesion is easily known in most cases [3], some cases may be missed diagnosed due to closed inter-morphology, such as hyperplasia [4]. Breast lesions are heterogeneous conditions and their classification is essential to achieve good clinical outcomes [5]. Premalignant breast lesions reign capricious risk for transformation to breast cancer, which necessitates an important decision to counter the potential evolution to breast cancer [6].

The histopathological diagnostic decision is a critical point, which is immensely challenging the histopathologists, particularly in borderline lesions. The final decision is critical because it is essential for subsequent patient's management. In borderline lesions, the distinction between benign and malignant components is challenging needing communitive evidence [7] [8]. Presence of connective tissue fibers including collagen, elastic and reticular fibers is well documented with breast lesions [9]. An increasing number of the argyrophilicnucleolar organizer regions (AgNORs) are associated with the cellular proliferative activity, which is encountered in some benign, premalignant and malignant lesions. Besides, AgNORs count can set up a consistent factor for the tumor grading and recognition, it is considered as a prognostic marker [10].

Although the recent advancement in molecular technology has improved the diagnostic acumen and knowledge of histo-pathogenesis in tumor diagnosis, particularly for frequently encountered tissues such as breast lesions [11], conventional histopathology still practiced as a routine technique. As the bulk of current research efforts are focusing on advanced diagnostic technology, which is time-consuming and expensive, additional research focusing on the strengthening of conventional histopathologic evidence is recommended to facilitate the potential diagnostic decision using routine histopathology. For that reason, the aim of this study was to evaluate the correlation between histochemical patterns of connective tissue fibers and NORs in breast lesions.

\section{Materials and Methods}

In this study, 50 formalin fixed paraffin wax embedded tissue blocks (belong to women attended with breast lesions) were retrieved from histopathology laboratory ( 25 were breast cancer and 25 were with benign breast lesions). All biopsies were obtained from females with breast lesions, their ages ranging from 17 to 85 years with a mean age of 39 years old. Patients with breast cancer $(n=25)$ were ascertained as the case group, and those with benign breast lesions were ascertained as a control group $(n=25)$. Patients' data were retrieved from laboratory records in Ribat University Hospital, Khartoum state-Sudan. Malignant breast lesions included a full coverage of the available samples during the period from Feb November 2017 to December 2018.

The previously diagnosed tissue specimens were reconfirmed by the pathologist. Three 5-microns thickness sections were made from each patient's block using Rotary Microtome. Out of the 4 sections, one was stained using Hematox- 
ylin and Eosin (H\&E) (to confirm histopathology diagnosis), one stained using Verhoeff's procedure (for elastic fibers = black color), one with Silvers method (Gordon \& Sweet's (for reticular fiber = black color)), and the remaining one was stained using argyrophilicnucleolar organizer regions (AgNORs). H\&E (Mayer's technique), Verhoeff's methods, Silver method, and van-Gieson's methods were applied adopting methods described elsewhere [12]. The intensities of the staining were qualitatively categorized in to $+++\mathrm{ve},++\mathrm{ve},+\mathrm{ve}$, and $-\mathrm{ve}$ according to the appearance of the fibers in the stained section.

NORs were stained applying AgNOR Staining Method. In this method; the working solution was freshly prepared by mixing one volume of $2 \%$ gelatin in $1 \%$ formic acid solution and two volumes of $50 \%$ aqueous silver nitrate solution. All sections were incubated with this silver solution for 30 minutes at room temperature in a dark medium, and they were protected in the dark until each slide was analyzed. Two investigators, blind to the study groups, analyzed the silver-stained cells under the light microscope (Olympus BX-51, Japan) at 1000x magnification. All sections were screened horizontally from left to right, and AgNORs were counted in the nuclei of the first 50 nucleated cells. Cells with pyknotic nuclei were not counted. The AgNORs count was made adopting the method described elsewhere [13].

AgNORs, which were visible as black-dark brown dots located within the nuclei of the cells, were counted; overlapped black dots were counted as one structure.

\section{Ethical Consent}

The study was approved by the ethical committee at the College of Medicine, University of Hail, Saudi Arabia. This is addition to an agreement letter taken from Ribat University Hospital authority.

\section{Statistical Analysis}

Statistical Analysis. SPSS version 17 statistical software was used for statistical analysis. The numeric results (AgNORs counts, and connective tissue fibers) were expressed as frequencies and percentages. The $\mathrm{X} 2$ test was used to compare the differences in categorical variables between the groups. Relationships between variables were analyzed using Pearson's correlation analysis. A P $<0.05$ was considered statistically significant.

\section{Results}

In the present study, 50 breast tissue biopsies were obtained from women with different breast lesions ( 25 were breast carcinoma, 19 were fibrocystic changes, 4 fibroadenomas, one was papilloma and one was fat necrosis). About 12/25 (48\%) of those with benign lesions were found at age group $<25$ years old, 5/25 (20\%) were at age range 26 - 35 years, 4/25 (16\%) were at age range 46 - 55 years and only one $(4 \%)$ was in age group $>56$ years old. A higher number of patients with 
breast carcinoma were detected at age range 36 - 45 years followed by age ranges $>56,26$ - 35, 46 - 55 and $<25$ years, representing 9/25 (36\%), 8/25 (32\%), $4 / 25$ (16\%), $3 / 25(12 \%)$, and $1 / 25$ (4\%), respectively, as described in Table 1 , Figure 1, Microphotograph 1.

Elastic fibers intensity was brought into being lessening in benign lesions and upturns in the direction of malignant lesions. Out of the 25 benign lesions, 9 (36\%), 8 (32\%), 7 (28\%) and 1 (4\%) were demonstrated with -ve, +ve, ++ve and $+++v e$, respectively, hence, out of the 25 malignant lesions, 1 (4\%), 8 (32\%), 9 (36\%) and 7 (28\%) were demonstrated with -ve, +ve, ++ve and +++ve, correspondingly. The intensity of elastic fibers was found to intensify towards neoplastic changes in breast cancer and this was found to be statistically significant $\mathrm{P}<$ 001 (Table 2, Figure 2, Microphotograph 1 and Microphotograph 2).

Reticular fiber has comparatively analogous colossal existence both in benign and malignant lesions. Out of the 25 carcinomas, 8 (32\%), $11(44 \%), 4(16 \%)$ and

Table 1. Study subjects by age and pathology.

\begin{tabular}{cccc}
\hline Age & Benign & Malignant & Total \\
\hline 25 years & 12 & 1 & 13 \\
$26-35$ & 5 & 4 & 9 \\
$36-45$ & 3 & 9 & 12 \\
$46-55$ & 4 & 3 & 7 \\
$56+$ & 1 & 8 & 9 \\
Total & 25 & 25 & 50 \\
\hline
\end{tabular}

Table 2. Distribution of pathology by intensity of histochemical staining.

\begin{tabular}{|c|c|c|c|c|}
\hline Variable & Category & Benign lesions & Malignant lesions & Total \\
\hline \multicolumn{5}{|c|}{ Elastic fibers (staining intensity) } \\
\hline & Negative (-ve) & 9 & 1 & 10 \\
\hline & Positive (+ve) & 8 & 8 & 16 \\
\hline & $++\mathrm{ve}$ & 7 & 9 & 16 \\
\hline & +++ ve & 1 & 7 & 8 \\
\hline & Total & 25 & 25 & 50 \\
\hline \multicolumn{5}{|c|}{ Reticular fibers (staining intensity) } \\
\hline & Negative (-ve) & 0 & 2 & 2 \\
\hline & Positive (+ve) & 4 & 4 & 8 \\
\hline & ++ ve & 9 & 11 & 20 \\
\hline & $+++\mathrm{ve}$ & 12 & 8 & 20 \\
\hline & Total & 25 & 25 & 50 \\
\hline \multicolumn{5}{|c|}{ Nucleolus organizer regions (AgNORs) mean count } \\
\hline & $<2$ mean dots & 18 & 8 & 26 \\
\hline & $2-4$ & 5 & 12 & 17 \\
\hline & $4-6$ & 1 & 4 & 5 \\
\hline & $>6$ & 1 & 1 & 2 \\
\hline & Total & 25 & 25 & 50 \\
\hline
\end{tabular}




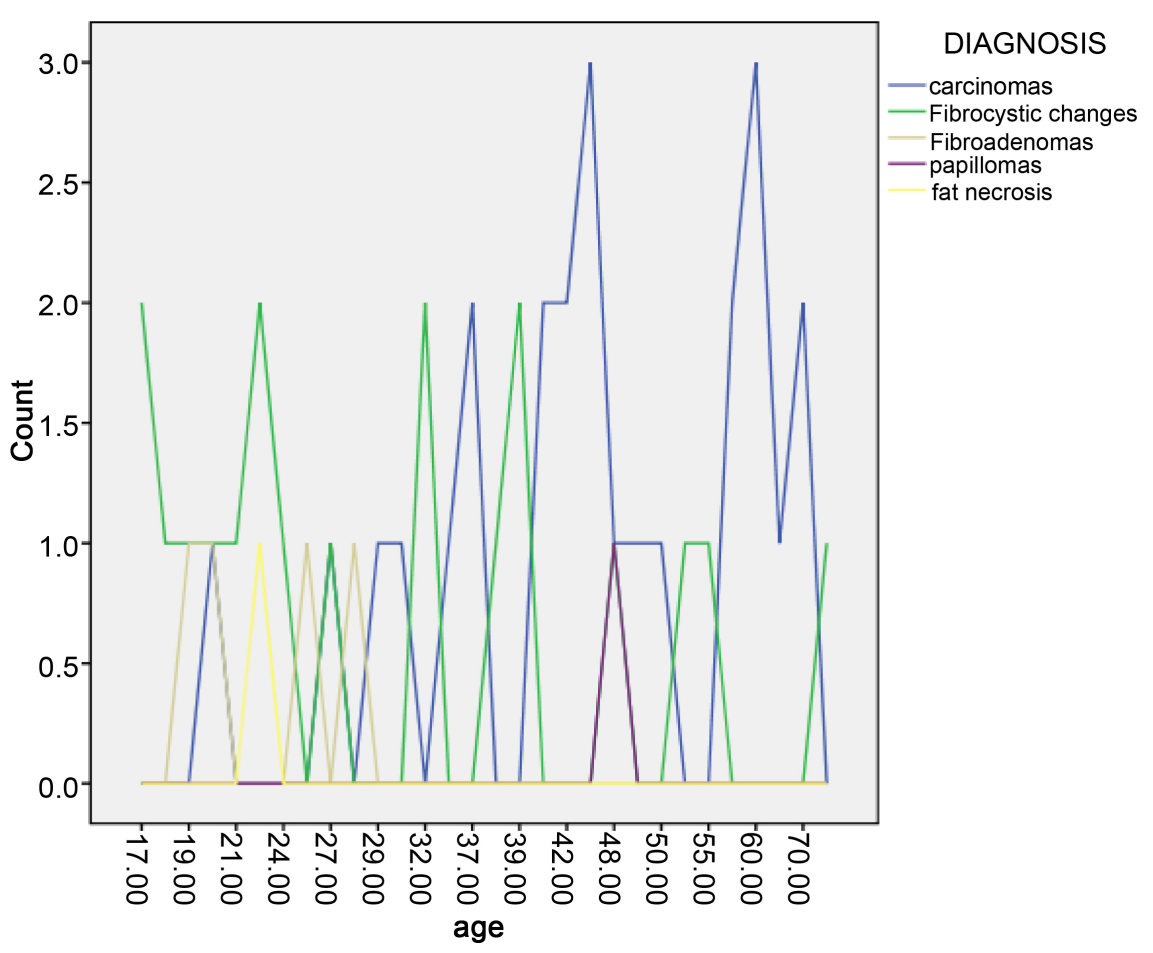

Figure 1. Description of age by breast lesion type.

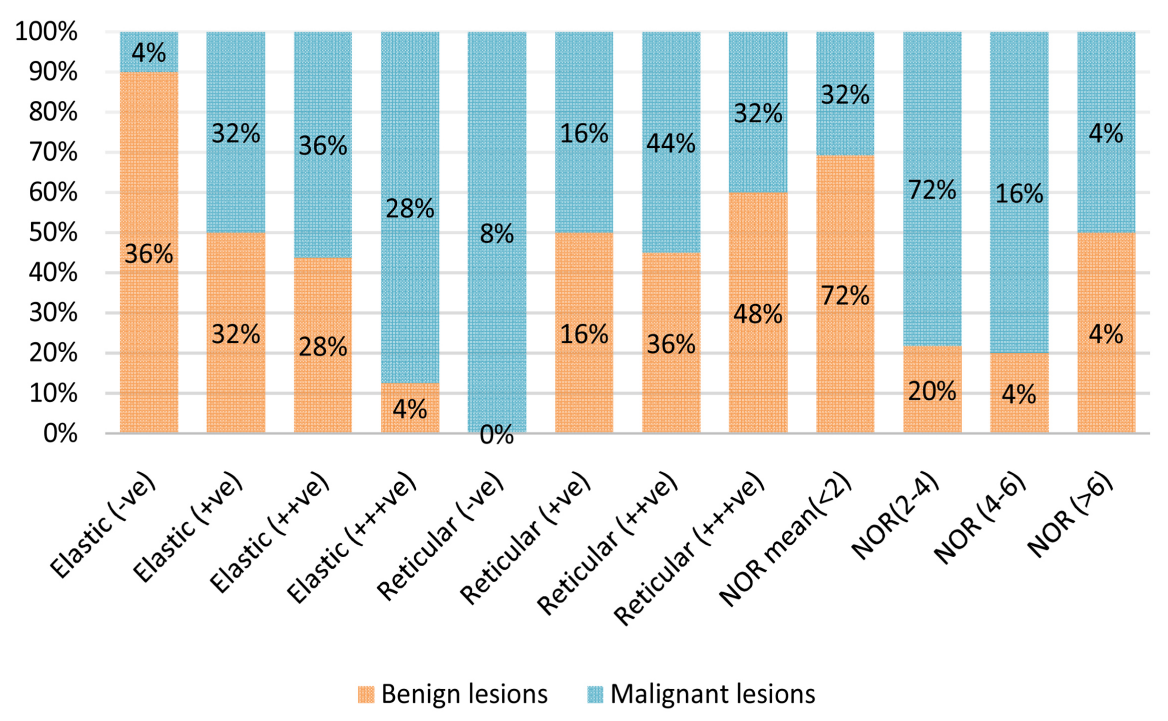

Figure 2. Histochemical reactions by lesion type.

$2(8 \%)$ cases were found with $+++\mathrm{ve},++\mathrm{ve},+\mathrm{ve}$, and -ve, in this order, compared to $12(48 \%)$ with +++ve, $9(36 \%)$ with $++v e$, and $4(16 \%)$ with +ve of the benign lesions (Table 2, Figure 2).

Mean AgNORs counts shown increased clusters among malignant cases equated to benign ones. The mean count of $<2$ dots, $2-4,4-6$ and $>6$ ANORs were shown in (malignant \& benign), (8 (32\%) \& 18 (72\%)), (12 (48\%) \& 5 (20\%)), (4 (16\%) \& $1(4 \%)),(1(4 \%) \& 1(4 \%))$, in that order, as indicated in Table 2, Figure 2. Mean AgNORs count was significantly increase with neoplastic 


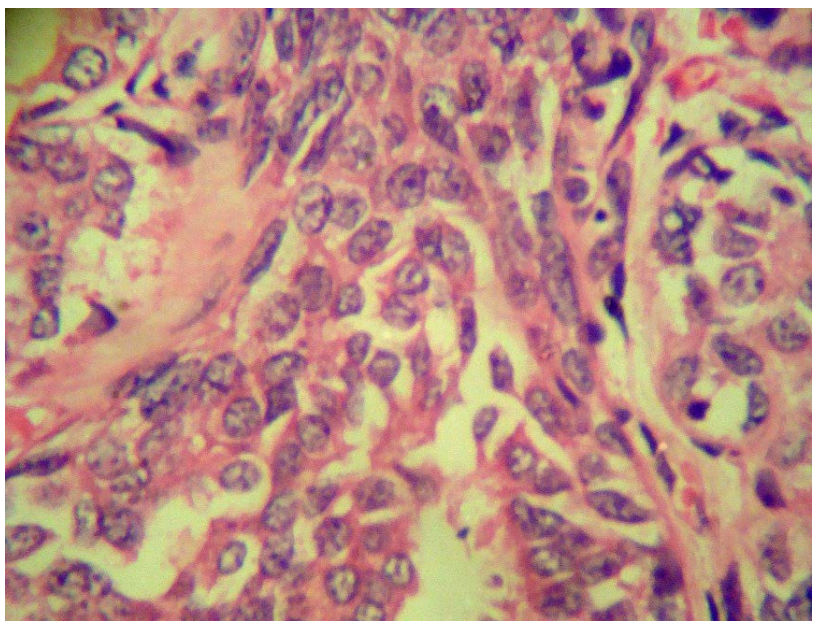

Microphotograph 1. Breast carcinoma (Hematoxylin and Eosin staining $400 \times)$.

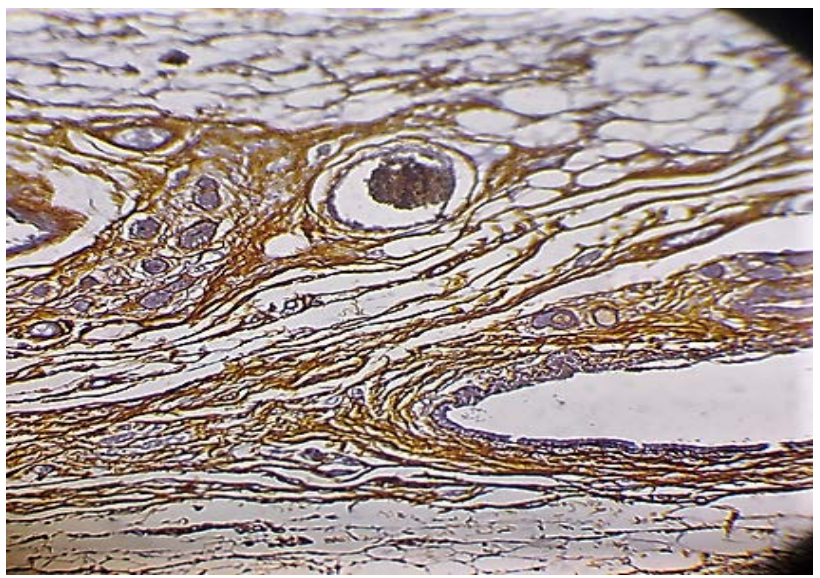

Microphotograph 2. Breast carcinoma (Verhoeff's' staining $100 \times)$.

proliferation $\mathrm{P}<0.005$.

About 17/25 (68\%) of the breast carcinoma were found with mean AgNORs count greater than 2 dots, hence 18/25 (72\%) of the benign breast lesions were found with mean AgNORs count less than 2 dots. Mean AgNORs count is significantly associated with neoplastic changes $\mathrm{P}<0.001$. Around 5/25 (20\%) of those with fibrocystic changes and 2/25 (8\%) with fibroadenoma were found with mean AgNORs greater than 2 dots, as seen in Table 3, Figure 3, Microphotograph 3 \& Microphotograph 4.

\section{Discussion}

The precise histopathologic diagnosis of a breast lesion is the first step towards the most appropriate inclusive patient's management. This study is an endeavor to promote the overall precision of conventional histopathologic diagnosis by boosting the histochemical pieces of evidence to distinguish between benign and malignant breast lesions constituents. 
Table 3. Breast lesion type by mean AgNORs count.

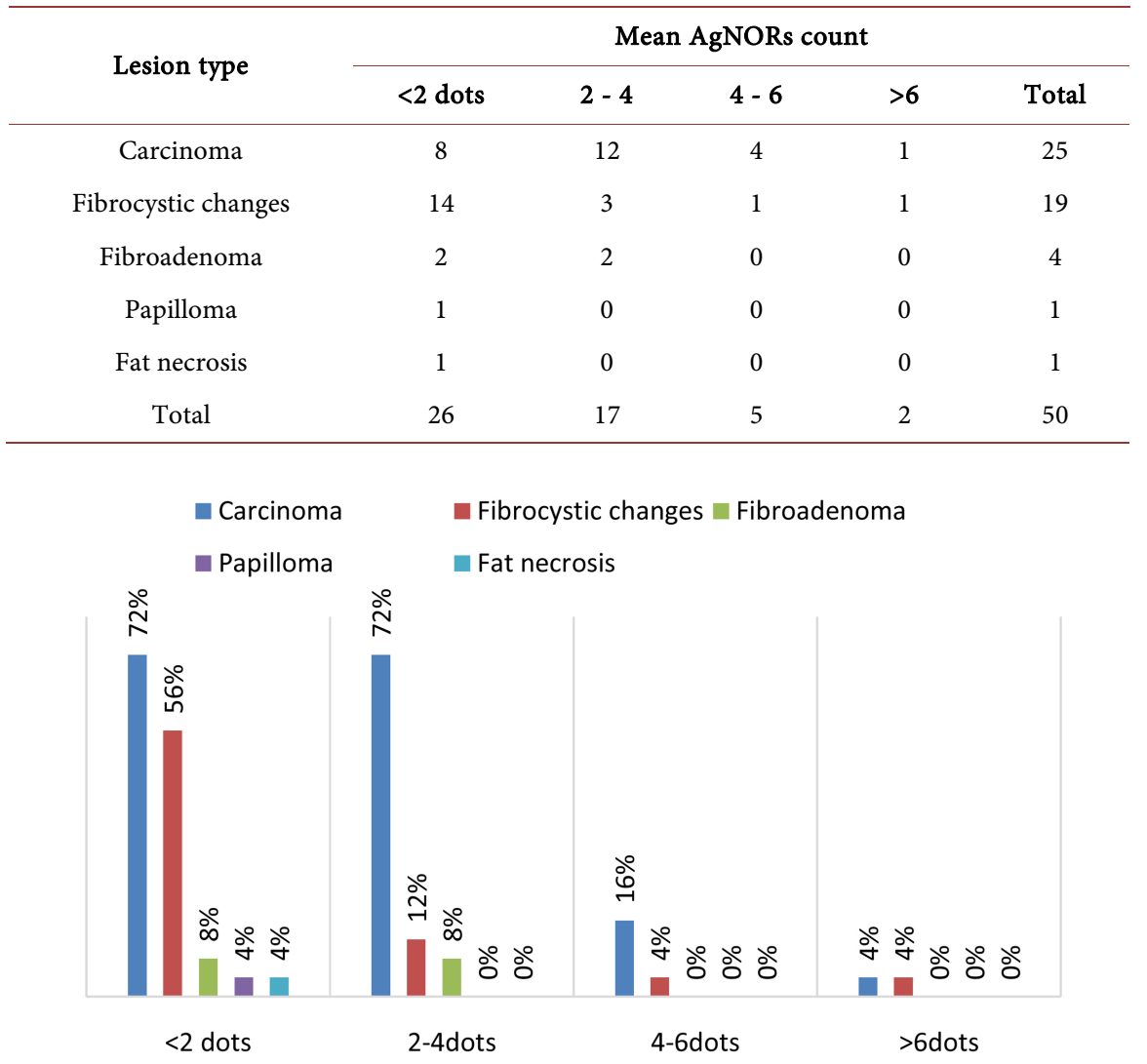

Figure 3. Breast lesion type by mean AgNORs count.

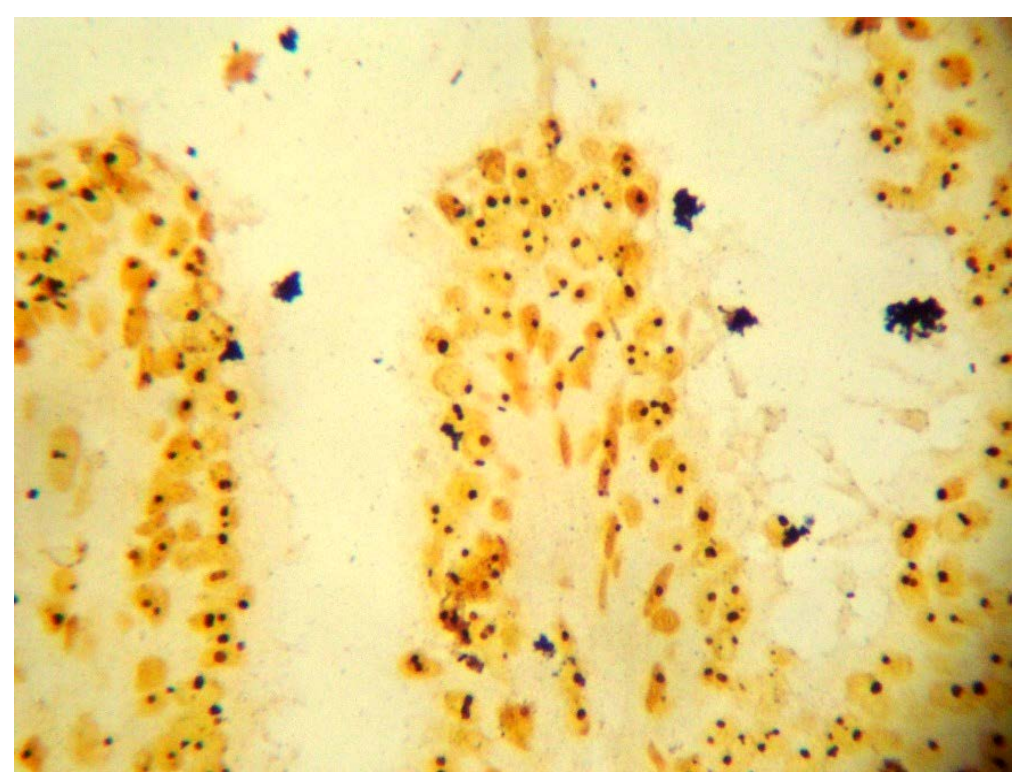

Microphotograph 3. Benign breast lesion showing nucleolar organizer regions (AgNORs) $\times 100$.

The evolution of elastic and reticular connective tissue morphologic patterns in the present study revealed a significant morphologic intensity in malignant 


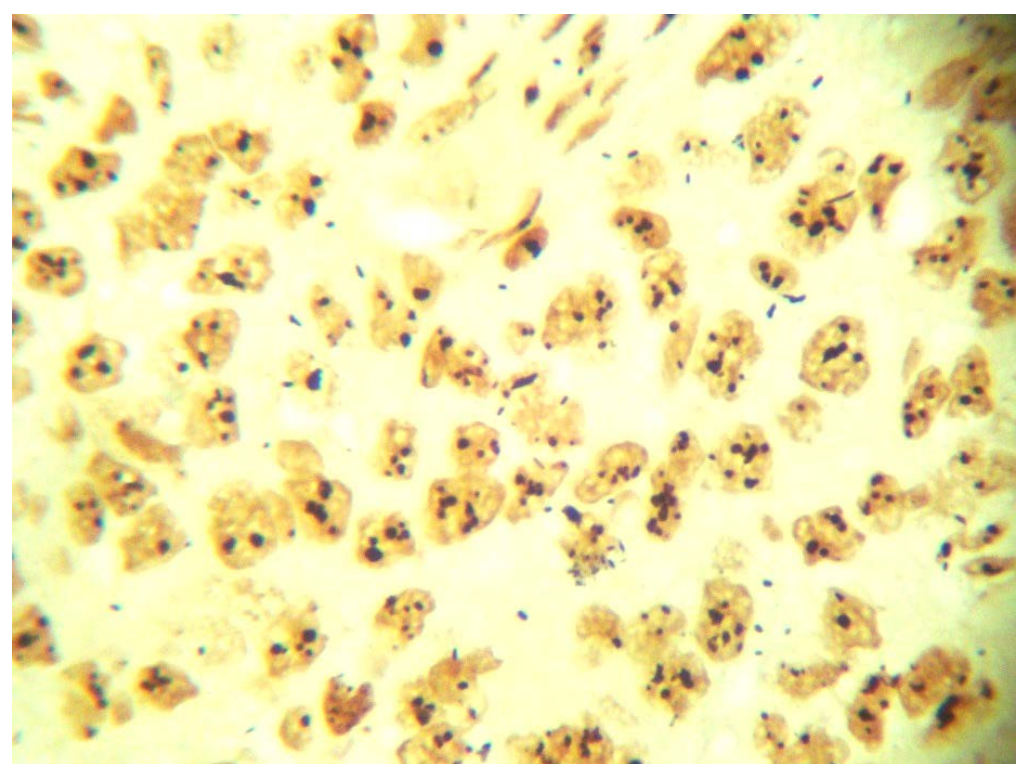

Microphotograph 4. Breast carcinoma showing nucleolar organizer regions (AgNORs) $\times 100$.

lesions compared to benign breast lesions $\mathrm{P}<0.001$. These findings were supporting a previous ultrastructural study of stromal breast carcinoma, which revealed elastic fibers combined with collagen and reticular fibers closely associated with carcinoma cells. In some cells, the fibers were seen within carcinoma cells with intermittent membrane as if they were made by malignant cells. Such annotations propose that breast carcinoma cells have a role in the formation of connective tissue fibers in association with stromal cells, as well as, promotion of stromal cellular components' proliferation [14]. Breast cancer has miscellaneous morphological patterns. Breast cancer stroma containing many constituents, such as proteoglycans and fibrous proteins [15]. Many studies have reported that the elastic fibers present in breast tissue as both discrete fibers in the stroma and bulk masses around ducts or small blood vessels. These elastic fibers are produced by stromal cells such as fibroblasts and myofibroblasts [16]. Besides its role as a shred of supporting diagnostic evidence, the elastic fiber was found to improve breast cancer survival [17], due to its correlation with estrogen receptor expression, which is responsive to anti-hormonal treatment [18].

In this sequence, a number of benign lesions revealed elastic and reticular fibers. Such findings were previously reported. Several breast benign tumors display extracellular matrix, collagen and reticular fibers in a variable quantity, whereas, elastic fibers were a noticeable feature in breast carcinoma compared to benign lesions [19].

Mean AgNORs counts showed increased clusters among malignant cases equated to benign ones. Mean AgNORs count significantly increased with neoplastic proliferation $\mathrm{P}<0.005$. AgNORs mean count is considered a valuable method for the assessment of cellular proliferation, which is commonly seen in premalignant and malignant tissues [20]. It was well-established that AgNORs 
mean count is a rapid, cost-effective, easy, and reproducible method that allows a clear quantitative distinction between malignant and benign tumors [21]. The utility of AgNORs count in breast cancer has been addressed by a number of studies. Beside it is utility as quantitative evidence for a distinction between benign and malignant lesions [22], some studies revealed its value as a prognostic factor in breast cancer [23]. The elevated number of AgNORs mean dots count is measured to be a diagnostic and prognostic factor due to its direct link to cell proliferation and ribosomal biogenesis [24]. As mean AgNORs count was also found to increase in some proliferative benign tumors, some scientists regarded it less diagnostic [25]. It was suggested that using image analysis may yield more improved diagnostic specificity [26].

The revised literature in this subject bared somewhat earlier research activities, which might be attributed to the makeover of scientists towards the new sophisticated techniques in the diagnosis of breast lesions. As conventional histopathology still the routine method in most histopathologic diagnostic settings, this study may inspire researcher to return and strengthen the diagnostic acumen of breast lesions.

\section{Conclusion}

In conclusion, demonstration of connective tissue fibers (particularly elastic fibers) can strength the diagnostic evidence for the conventional histopathological diagnosis. Mean AgNORs count is an important quantitative marker in breast cancer diagnosis. Further efforts are required to develop these diagnostic markers in order to ease the challenges fronting pathologists when diagnosing borderline breast lesions.

\section{Data Availability Statement}

The data used to support the findings of this study are included in the article.

\section{Acknowledgements}

The author would like to thank people at Ribat University Hospital, for their help and offering the samples.

\section{Conflicts of Interest}

Author declares no conflict of interest.

\section{Funding}

The work was supported by the author.

\section{References}

[1] Globocan (2018) Breast: Cancer Incidence and Mortality Statistics Worldwide and by Region, 2018. http://gco.iarc.fr/today/data/factsheets/cancers/20-Breast-fact-sheet.pdf 
[2] Morrow, M., Schnitt, S.J. and Norton, L. (2015) Current Management of Lesions Associated with an Increased Risk of Breast Cancer. Nature Reviews Clinical Oncology, 12, 227-238. https://doi.org/10.1038/nrclinonc.2015.8

[3] Asirvatham, J.R., Falcone, M.M. and Kleer, C.G. (2016) Atypical Apocrine Adenosis: Diagnostic Challenges and Pitfalls. Archives of Pathology \& Laboratory Medicine, 140, 1045-1051. https://doi.org/10.5858/arpa.2016-0238-RA

[4] Dion, L., Racin, A., Brousse, S., et al. (2016) Atypical Epithelial Hyperplasia of the Breast: State of the Art. Expert Review of Anticancer Therapy, 16, 943-953. https://doi.org/10.1080/14737140.2016.1204916

[5] Yeo, S.K. and Guan, J.L. (2017) Breast Cancer: Multiple Subtypes within a Tumor? Trends in Cancer, 3, 753-760. https://doi.org/10.1016/j.trecan.2017.09.001

[6] Walaszek, K., Lower, E.E., Ziolkowski, P. and Weber, G.F. (2018) Breast Cancer Risk in Premalignant Lesions: Osteopontin Splice Variants Indicate Prognosis. British Journal of Cancer, 119, 1259-1266. https://doi.org/10.1038/s41416-018-0228-1

[7] Agoumi, M., Giambattista, J. and Hayes, M.M. (2016) Practical Considerations in Breast Papillary Lesions: A Review of the Literature. Archives of Pathology \& Laboratory Medicine, 140, 770-790. https://doi.org/10.5858/arpa.2015-0525-RA

[8] Jorns, J.M. (2016) Papillary Lesions of the Breast: A Practical Approach to Diagnosis. Archives of Pathology \& Laboratory Medicine, 140, 1052-1059. https://doi.org/10.5858/arpa.2016-0219-RA

[9] Montes, G.S. (1996) Structural Biology of the Fibers of the Collagenous and Elastic Systems. Cell Biology International, 20, 15-27. https://doi.org/10.1006/cbir.1996.0004

[10] Winzer, K.J., Bellach, J. and Hufnagl, P. (2013) Long-Term Analysis to Objectify the Tumor Grading by Means of Automated Microscopic Image Analysis of the Nucleolar Organizer Regions (AgNORs) in the Case of Breast Carcinoma. Diagnostic Pathology, 8, 56. https://doi.org/10.1186/1746-1596-8-56

[11] Wei, S. (2016) Papillary Lesions of the Breast: An Update. Archives of Pathology \& Laboratory Medicine, 140, 628-643.

[12] Bancroft, J.D. and Gamble, M. (2011) Theory and Practice of Histological Techniques. 6th Edition, Churchill Livingstone/Elsevier, London, 121-135.

[13] Ahmed, H.G. and Babiker, A.E. (2009) Assessment of Cytological Atypia, AgNOR and Nuclear Area in Epithelial Cells of Normal Oral Mucosa Exposed to Toombak and Smoking. Rare Tumors, 1, e18. https://doi.org/10.4081/rt.2009.e18

[14] Ghosh, L., Ghosh, B.C. and Das Gupta, T.K. (1980) Ultrastructural Study of Stroma in Human Mammary Carcinoma. The American Journal of Surgery, 139, 229-232. https://doi.org/10.1016/0002-9610(80)90260-3

[15] Frantz, C., Stewart, K.M. and Weaver, V.M. (2010) The Extracellular Matrix at a Glance. Journal of Cell Science, 123, 4195-4200. https://doi.org/10.1242/jcs.023820

[16] Nakanishi, I., Moriizumi, T., Ooi, A., Oda, Y. and Kajikawa, K. (1983) An Ultrastructural Study on Periductalelastosis in Human Breast Tumors. Acta Pathologica Japonica, 33, 761-772.

[17] Fisher, E.R., Anderson, S., Redmond, C. and Fisher, B. (1993) Pathologic Findings from the National Surgical Adjuvant Breast Project Protocol B-06. 10-Year Pathologic and Clinical Prognostic Discriminants. Cancer, 71, 2507-2514.

https://doi.org/10.1002/1097-0142(19930415)71:8<2507::AID-CNCR2820710813>3. $\underline{0 . \mathrm{CO} ; 2-0}$

[18] Masters, J.R., Millis, R.R., King, R.J. and Rubens, R.D. (1979) Elastosis and Re- 
sponse to Endocrine Therapy in Human Breast Cancer. British Journal of Cancer, 39, 536-539. https://doi.org/10.1038/bjc.1979.98

[19] Pai, M.R., Pai, K.N., Rao, R.V., Naik, R. and Shankarnarayana, B.P. (1999) Connective Tissue Stromal Changes in Tumors and Tumor-Like Lesions of the Breast. Indian Journal of Pathology and Microbiology, 42, 327-332.

[20] Akhtar, G.N., Chaudhry, N.A., Tayyab, M. and Khan, S.A. (2004) AgNOR Staining in Malignant and Benign Effusions. Pakistan Journal of Medical Sciences, 20, 29-32.

[21] Costa Ade, L., de Araújo, N.S., Pinto Ddos, S. and de Araújo, V.C. (1999) PCNA/AgNOR and Ki-67/AgNOR Double Staining in Oral Squamous Cell Carcinoma. Journal of Oral Pathology \& Medicine, 28, 438-441. https://doi.org/10.1111/j.1600-0714.1999.tb02103.x

[22] Ahmed, H.G., Al-Adhraei, M.A. and Ashankyty, I.M. (2011) Association between AgNORs and Immunohistochemical Expression of ER, PR, HER2/neu, and p53 in Breast Carcinoma. Pathology Research International, 2011, Article ID: 237217. https://doi.org/10.4061/2011/237217

[23] Rzymowska, J. (1997) AgNOR Counts and Their Combination with Flow Cytometric Analyses and Clinical Parameters as a Prognostic Indicator in Breast Carcinoma. Tumori, 83, 938-942. https://doi.org/10.1177/030089169708300613

[24] Maria Luiza, S.M., Benedicto, C., Russo, J., Planding, W. and Schenck, U. (2008) Image Analysis of the AgNOR Response in Ras-Transformed Human Breast Epithelial Cells. Acta Histochemica, 110, 210-216.

https://doi.org/10.1016/j.acthis.2007.10.016

[25] Sivrides, E., Anastasiadis, P. and von Lüdinghausen, M. (1992) Argyrophilic Staining for Nucleolar Organizer Region (AgNOR). A Suitable Methodology for Differential Diagnosis of Breast Lesions? Zentralblatt fur Pathologie, 138, 103-107.

[26] Ruschoff, J., Neumann, K., Contractor, H., Plate, K. and Thomas, C. (1990) Assessment of Nucleolar Organizer Regions by Automatic Image Analysis in Breast Cancer: Correlation with DNA Content, Proliferation Rate, Receptor Status, and Histopathological Grading. Journal of Cancer Research and Clinical Oncology, 116, 480-485. 